\title{
Pre-Treatment Imaging in the Surgical Management of Endometriosis
}

\author{
Raluca Gabriela SUBA ${ }^{1}$, Octavian ENCIU², Livia STANCIULESCU ${ }^{3}$, Razvan STANCIULESCU ${ }^{4}$, \\ Bogdan MARINESCU'
}

\begin{abstract}
Background: Preoperative imaging assessment is essential to draw an accurate map of endometriotic lesions. Knowledge of the extension and severity of disease is paramount for the surgical team in order to plan the type of surgery, complete the operating team and properly inform the patient with details of the risks. Material and Method: Transvaginal ultrasound is the first-line imaging technique for ovarian and deep infiltrating endometriosis, but the accuracy of the diagnosis is proportional with the experience of the operator. Respecting the four steps of ultrasound evaluation technique decreases the probability of misdiagnosis. Step 1 include evaluation of the uterus and adnexa, step 2 - evaluation of "soft marker", step 3 - assessment of the Pouch of Douglas using "sliding sign" and step 4 - assessment of anterior pelvic compartment (urinary bladder, uterovesical region and ureters) and posterior pelvic compartment (rectovaginal septum, posterior vaginal fornix, uterosacral ligaments, rectum and sigmoid). MRI is performed as an additional examination in complex cases prior to surgery, in symptomatic patients with negative or equivocal ultrasound findings and it can be useful for diagnosis of multiple sites of deep infiltrating endometriosis. Results: Important information from recent guidelines and relevant literature are highlighted. Ovarian and deep endometriosis diagnosed by ultrasound scan and MRI imaging - case series (personal experience) will be commented. Conclusion: As with cancer pathology, the success of treatment depends on complete excision of the endometriotic lesions. Rigorous imaging investigation avoids "the tip of the iceberg" mirage and enhances the quality of medical care.
\end{abstract}

Keywords: endometriosis, preoperative diagnosis, ultrasound, MRI, lesion map, quality of life, EHP-30.

\section{Rezumat}

Introducere: Evaluarea imagistică preoperatorie este esențială în constituirea unei hărți a leziunilor de endometrioză. Cunoașterea extinderii și severității bolii este extrem de importantă pentru echipa chirurgicală, astfel încât acesta să poată planifica tipul intervenției chirurgicale, să completeze echipa operatorie și să informeze pacienta asupra riscurilor operatorii. Material și metodă: Ecografia transvaginală este investigația imagistică de primă intenție în diagnosticul endometriozei ovariene și profunde, dar acuratețea diagnosticului este proporțională cu experiența operatorului. Urmărind tehnica evaluării ultrasonografice în 4 timpi, probabilitatea ratării diagnosticului scade. Timpul 1 include evaluarea uterului și anexelor, timpul 2 - evaluarea sensibilității și mobilității anexelor, timpul 3 - evaluarea statusului fundului de sac Douglas cu ajutorul "sliding sign" și timpul 4 - evaluarea compartimentului anterior (vezică urinară, spațiul vezico-uterin, uretere) și a compartimentului posterior (sept rectovaginal, fund de sac vaginal posterior, ligamente uterosacrate, rect, sigmoid). RMN reprezintă o investigație suplimentară care trebuie recoman-

\footnotetext{
${ }^{1}$ "Prof. Dr. Panait Sarbu" Clinical Hospital of Obstetrics and Gynecology, Bucharest, Romania

${ }^{2}$ Department of Surgery, Elias University Emergency Hospital, Bucharest, Romania

${ }^{3}$ MedicalES Imaging Clinic, Bucharest, Romania

${ }^{4}$ Department of Radiology, Elias University Emergency Hospital,

Bucharest, Romania
}

\section{Corresponding author.}

Octavian ENCIU, Elias University Emergency Hospital, 17 Marasti Boulevard, $1^{\text {st }}$ District, 011461 , Bucharest, Romania.

E-mail: esoctavian@gmail.com 
dată preoperator, pentru toate cazurile complexe, la pacientele simptomatice cu examinare ecografică negativă sau echivocă și de asemeni este utilă la pacientele cu noduli endometriozici multipli la nivelul tubului digestiv. Rezultate: Informații esențiale din ghiduri actuale și literatura de specialitate vor fi evidențiate. Sunt analizate si comentate o serie de cazuri de endometrioza ovariană și endometrioza profundă cu diagnostic ecografic și RMN. Concluzii: Similar cu patologia neoplazică, succesul tratamentului depinde de excizia completă a leziunilor endometriozice. Examinarea imagistică riguroasă evită mirajul "primei leziuni" pentru și crește calitatea actului medical.

Cuvinte cheie: endometrioză, diagnostic preoperator, ultrasonografie, RMN, hartă lezională, calitatea vieții, EHP-30.

\section{INTRODUCTION}

It is essential to map the endometriosis lesions using preoperative imaging evaluation in order to offer to the surgical team details about the extension and severity of the disease. Establishing an accurate diagnosis and preoperative staging, gives the possibility for optimal therapeutic plan, to complete the surgical team with colo-rectal surgeons or urologists, to inform the patient of foreseeable intraoperative complications and to obtain informed consent for each procedure.

To avoid suboptimal treatment and multiple surgical interventions, patients with severe endometriosis (stage III-IV) must be referred to high volume specialized centers ${ }^{1}$.

Transvaginal ultrasound and MRI are not competing but rather complementary investigations. Ultrasound has the advantage of being readily available, routinely performed, at low cost, with minimal patient discomfort and it's a real time evaluation with the opportunity to mobilize the uterus and the adnexa. Meanwhile, MRI offers essential details in defining rectal endometriosis nodules (locations, size, stenosis grade, parietal infiltration stage) and also can diagnose endometriotic lesions located above the sigmoid colon.

According to current guidelines, transvaginal ultrasound comes first as recommendation during evaluation of patients with suspected endometriosis ${ }^{2,3}$. Every patient with dysmenorrhea or dyspareunia that can be related with endometriosis and/or diagnosed with endometrioma should receive the ultrasound protocol of deep endometriosis.

MRI is indicated in selected cases, for example in symptomatic patients with negative ultrasound findings or in suspected cases of deep endometriosis with multiple locations, although there isn't enough published data concerning the indication of MRI in the evaluation of pelvic endometriosis ${ }^{4-6}$. In order to obtain a high accuracy diagnosis, both investigations must be performed by experienced specialists in endometriosis.

\section{MATERIAL AND METHOD}

Transvaginal ultrasound is useful and highly accurate for endometriomas and deep endometriosis diagno$\operatorname{sis}^{5,7}$.

The menstrual cycle does not influence ultrasound evaluation; emptying the rectum and bowel preparation with contrast medium is adjuvant but not mandato$\mathrm{ry}^{8}$. High-resolution transvaginal scan is recommended to enhance the quality of imaging in evaluation of the rectum and sigmoid colon'.

The IDEEA Group created a protocol for ultrasound evaluation that brings multiple benefits for daily practice: standardization of technique, mandatory evaluation of all pelvic compartments, uniformization of terminology and definitions for endometriotic lesions ${ }^{3}$. This protocol is useful in current practice by increasing the rate of detection of deep endometriotic lesions and facilitates multicenter research.

The protocol calls for a four-step ultrasound evaluation:

- Step one is routinely performed in every ultrasound examination and represents the evaluation of the uterus and adnexa searching for of signs of adenomyosis and endometriomas;

- Step two checks the mobility and specific tenderness of the uterus and ovaries, the so-called "soft markers", using bimanual technique. An ultrasound sign that indicates the presence of 
adhesions and the absence of ovarian mobility is "kissing ovaries" sign - this finding indicates an advanced stage of the disease, which can be more frequently associated with Fallopian obliteration $(92,6 \%)$ and bowel endometriosis. $(18,5 \%)^{10}\left(\mathrm{Fi}^{-}\right.$ gure 1).

- Step three evaluates the status of the pouch of Douglas (POD) using the ,sliding sign”. A positive sliding sign in the retrocervical region and the level of the upper uterus indicates an unobliterated POD.

- Step four aims to identify the presence of endometriotic nodules in the anterior compartment (urinary bladder, uterovesical region) and in the posterior compartment (rectovaginal septum, posterior vaginal fornix, uterosacral ligaments, rectum and sigmoid).

Assessment of the mobility between uterus and posterior region of the bladder is paramount because often bladder endometriotic nodules arise from the uterus. Identifying a hypoechogenic wall thickness or nodule with low Doppler signal, involving the muscularis or submucosa of the bladder with a negative "sliding sign” in the anterior compartment are highly suggestive for the diagnosis of urinary bladder endometriotic nodu$1 \mathrm{e}^{11}$ (Figure 2).

The normal uterosacral ligament is not visible during ultrasound examination, unless it is surrounded by fluid. Pathological uterosacral ligament is visible in the absence of fluid if its proximal region is thickened, nodular and hypoechogenic ${ }^{8}$ (Figure 3).

Transvaginal ultrasound has the great advantage of real-time bimanual examination in detecting adhesions in the posterior compartment. Furthermore, the four separate rectosigmoid wall layers have different echogenicity and this allows staging of parietal infiltration (Figure 4).

The disadvantage of transvaginal ultrasound is that it can't precisely predict the grade of stenosis because the distention of the bowel cannot be estimated. The distance between the nodule and the anal orifice can be estimated at best taken into consideration that the location of POD is at $7-9 \mathrm{~cm}$ from the anal orifice. The gynecologist has the possibility to use a transrectal probe to estimate more precise the distance to the anal orifice, but this method has low compliance among patients ${ }^{12}$.

Previous published data sustain a high accuracy of transvaginal ultrasound in the diagnosis of endometrioma, peri-adnexal adhesions, POD obliteration and bladder nodules ${ }^{13}$. Regarding the uterosacral ligament, sensitivity is lower, without major impact on surgical protocol. ${ }^{14} \mathrm{~A}$ review that included 10 studies demonstrated a sensitivity of $67-98 \%$ and a specificity of $92-$ $100 \%$ for bowel endometriotic lesions ${ }^{15}$.

To conclude, a complete imagistic report consists in describing "hard markers” - endometriomas (dimensions, number, typical/atypical aspect), „soft markers”,

Figure 1. "Kissing ovaries".

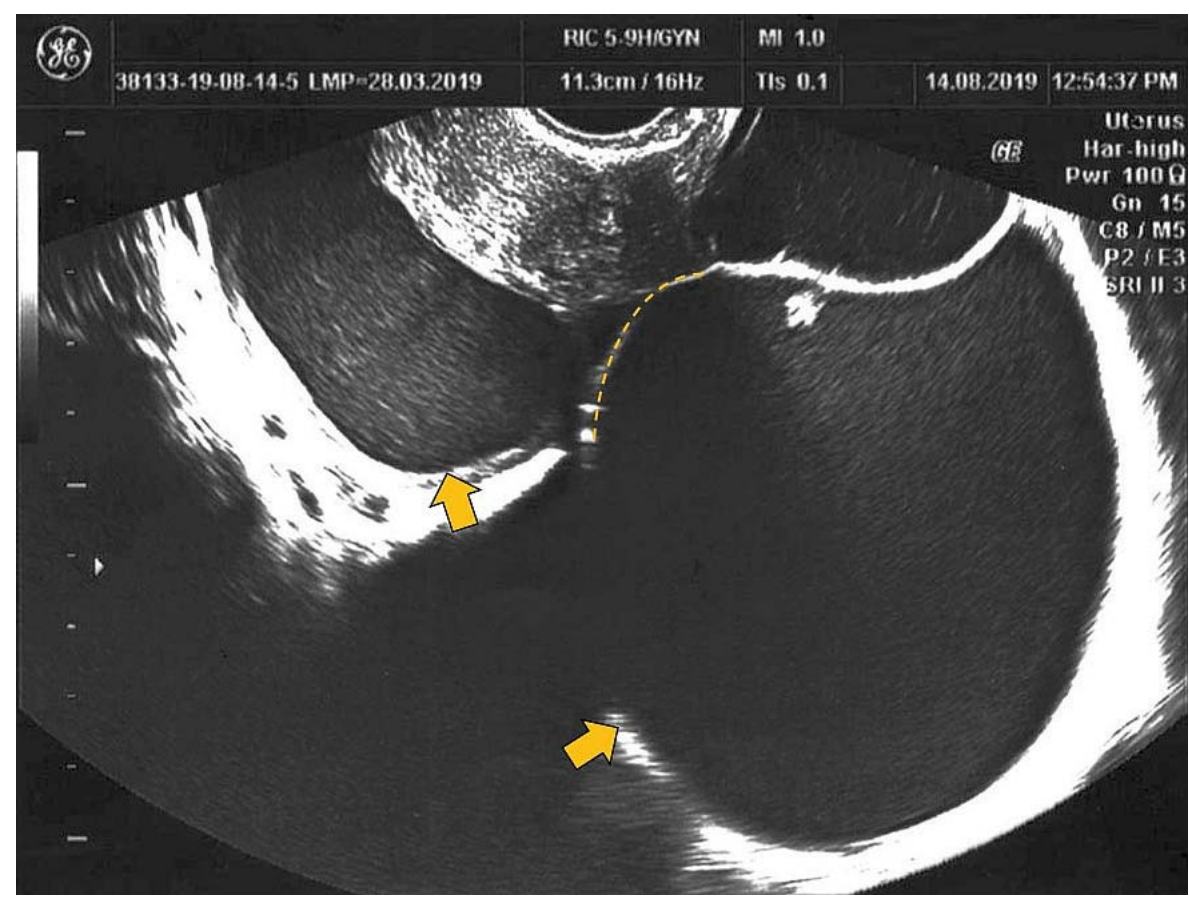


Figure 2. Urinary Bladder Nodule.

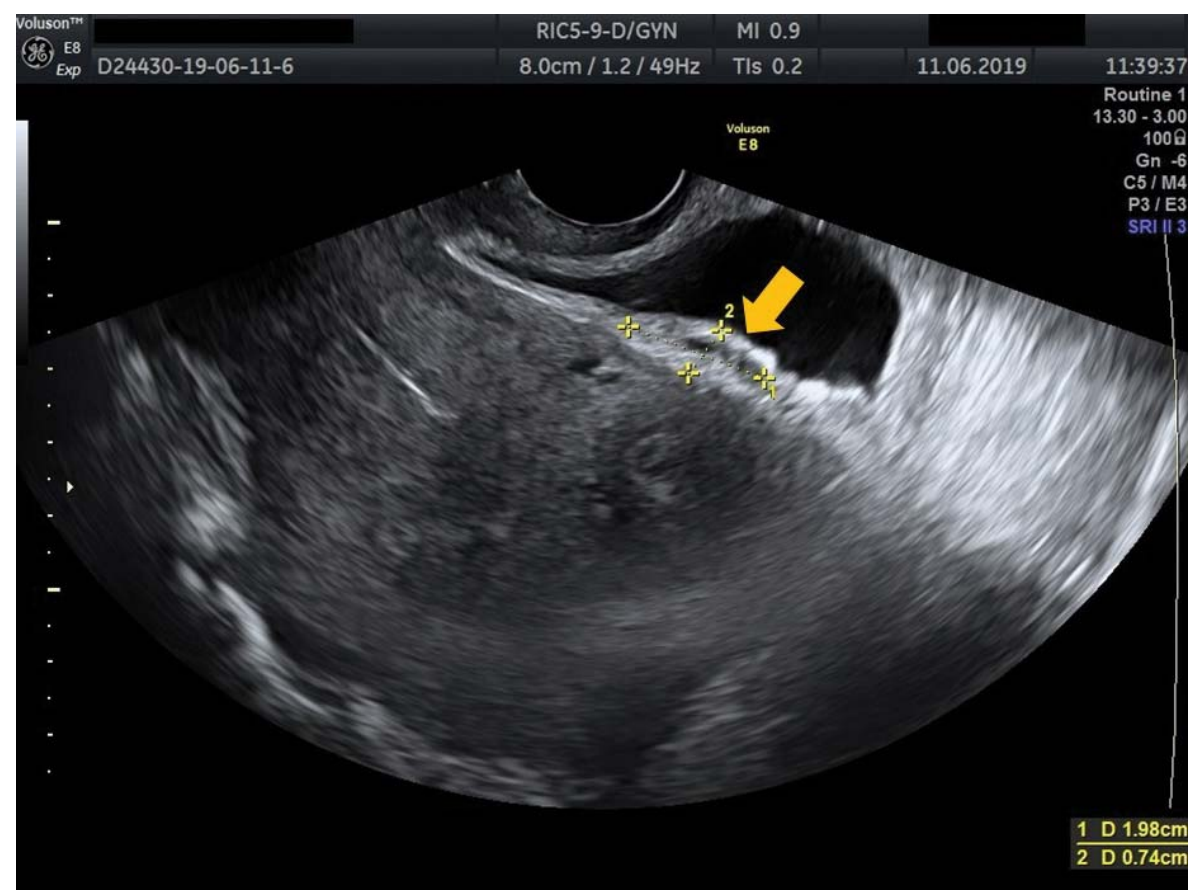

Figure 3. Thickened, nodular and hypoechogenic uterosacral ligament.

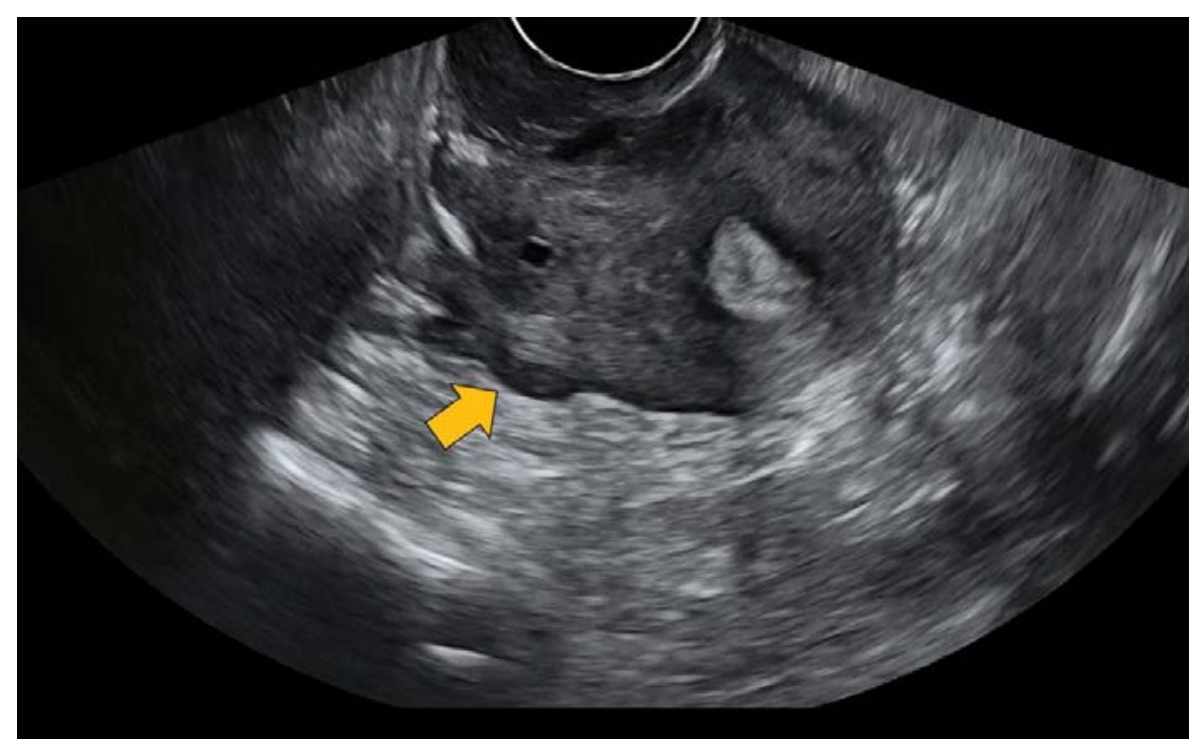

„sliding sign”, rectal/sigmoidian colon nodules (dimensions, location, distance from the anal orifice, the depth of wall infiltration, stenosis grade), bladder nodules, ureterohydronephrosis.

This information is extremely important for the surgeon in elaborating the therapeutic plan, choosing the type of surgical procedure, estimating operating time and the possibility of multidisciplinary involvement during the procedure.

Not so often, these goals are difficult if not impossible to achieve just by using transvaginal ultrasound, this is where MRI brings light in a dark landscape. 


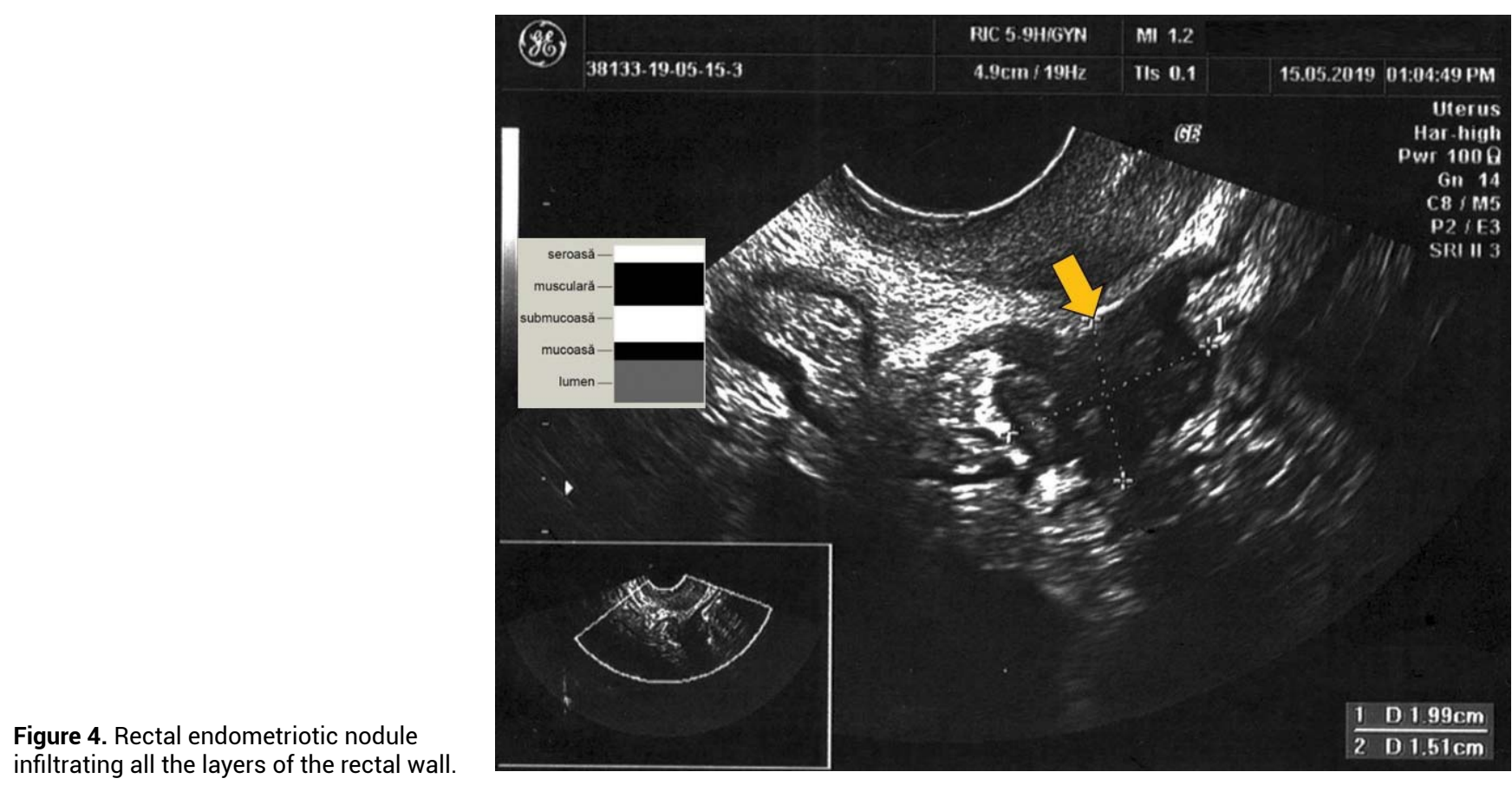

infiltrating all the layers of the rectal wall.

MRI is an advantageous technique because it offers multiplanar evaluation, high resolution, lack of radiation and the possibility of abdominal and pelvic complete evaluation in a single scan ${ }^{16}$. Compared to ultrasound, it can visualize in one slide the anatomic relation of the uterus and recto-sigmoid colon, therefore can easily identify and differentiate a nodule located in the inferior, medium or upper rectum or the recto-sigmoid junction. Ultrasound can only estimate the location of the nodule based on anatomical landmarks: lesions situated bellow the insertion of uterosacral ligament on the cervix are considered lower (sub-peritoneal) anterior rectal lesions, while nodules located above are considered upper anterior rectal lesions; nodules situated at the level of uterine fundus are located at the rectosigmoid junction and the ones above this limit belong to the sigmoid. The hyper anteverted and/or retroverted uterine position can misleading regarding the correct localization of rectal/ sigmoid nodules.

During ultrasound examination, the distance from the anal orifice is arbitrary evaluated while MRI can directly measure the distance taken into consideration the rectosigmoid curves. It is important for the surgeon to know the exact location of rectal nodules because low rectal resections are more difficult to perform, the need for a temporary stoma may occur and the risk of complications may increase manifold. In the light of the above, patients must express an informed consent for stoma and time should be taken to explain the risks and possible complications.

Endometriosis nodules that infiltrate the rectal muscularis should be completely resected, this implies a certain type of rectal resection ${ }^{17}$. For this reason, it is essential to know the grade of parietal infiltration for choosing the correct surgical technique, and both imaging investigations, ultrasound and MRI satisfy this purpose. The majority of endometriotic lesions that have penetrated the muscularis and submucosa are found to affect at least $40 \%$ of the circumference of the rectal wall ${ }^{18}$.

Predicting the stenosis grade and the dimension of the nodule is mandatory for choosing the correct type of resection - nodulectomy, discoid or segmental bowel resection. MRI and ultrasound are limited in measuring the maximum grade of bowel distention, water enema with a 24 Fr Foley rectal catheter could improve this aspect. Rectal and vaginal opacification with sonographic gel is suggested as an option that could provide better evaluation of $\mathrm{POD}$, the rectovaginal septum, and rectosigmoid endometriosis ${ }^{4}$.

In summary, MRI brings diagnosis reliability, increases the recognition of subperitoneal lesions and the ones covered by adhesions, offers precise data of nodules characteristics and can provide a road map that 
allows presurgical counseling and complete ablation of all possible endometriotic lesions.

\section{RESULTS}

Case 1 - A 43 years old woman with one natural labor 10 years prior describing low intensity dysmenorrhea 3-VAS, without dyspareunia, sporadic constipation without rectal bleeding was referred for routine examination.

A $3.97 / 3.08 \mathrm{~cm}$ ground glass adnexal cystic mass suggestive of endometrioma was diagnosed by ultrasound. IDEA protocol for endometriosis was applied - posterior compartment evaluation by angulating ultrasound probe towards the rectum identified a hypoechoic non-homogenous, non-vascularized nodule that infiltrates all the layers of the rectal wall. The mucosa of the rectal wall was intensely retracted resulting in the so-called „Indian headdress sign” (Figure 5). The nodule measured $4.02 / 1.45 / 3 \mathrm{~cm}$.

MRI scan confirmed the diagnosis and further evaluated a $50 \%$ degree of stenosis at the mid and upper level of the rectum, approximately $15 \mathrm{~cm}$ from the anal orifice. The MRI protocol lacked intrarectal gel instillation (T2 sagittal coronal and axial $3.5 \mathrm{~mm}$ slices, oblique axial and oblique coronal at the level of the uterus, T1 gradient with saturated fat in axial plane) (Figure 6).

Given the lack of symptoms, expected menopause $(\mathrm{FSH}=60 \mathrm{mUI} / \mathrm{ml})$ and moderate degree of rectal stenosis, a "wait and see" management was suggested with 6 months ultrasound and MRI reevaluation.

Case 2 - 39-year-old woman with one natural labor 8 years prior describing dysmenorrhea VAS-8, dyspareunia VAS-7, chronic pelvic pain VAS-5, chronic constipation, rectal bleeding during menstrual cycle and overall severe quality of life impairment - EHP-30 score 81.48 .

Ultrasound examination demonstrated "kissing ovaries" - both ovaries were located posterior to the uterus with two endometriotic cysts of $6 / 5.2 / 4 / 3 \mathrm{~cm}$ and 4.08/3/2.35 cm; negative "sliding sign" at the retrocervical region and at the uterine fundus - completely obliterated pouch of Douglas. In the posterior compartment, at the level of the uterosacral ligaments, a $3.47 / 2.37 \mathrm{~cm}$ well defined hypoechoic nodule that infiltrates all the layers of the rectal wall was visualized (this corresponds to the medium rectum) (Figure 7).

Pelvic MRI after enema and intravaginal and intrarectal gel instillation diagnosed T2 low signal intensity

Figure 5. Ground glass adnexal endometrioma and rectal nodule with "Indian headdress sign".

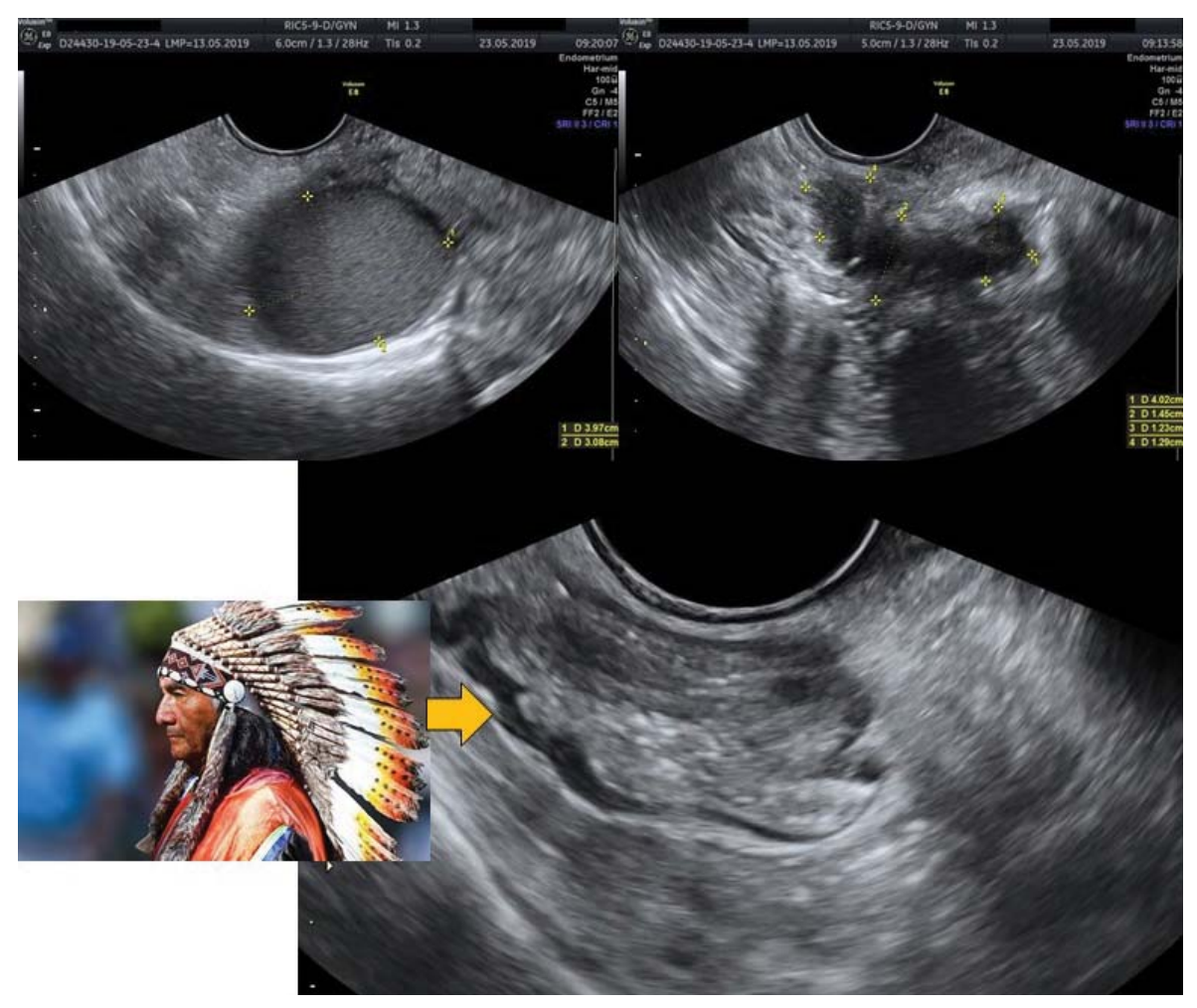




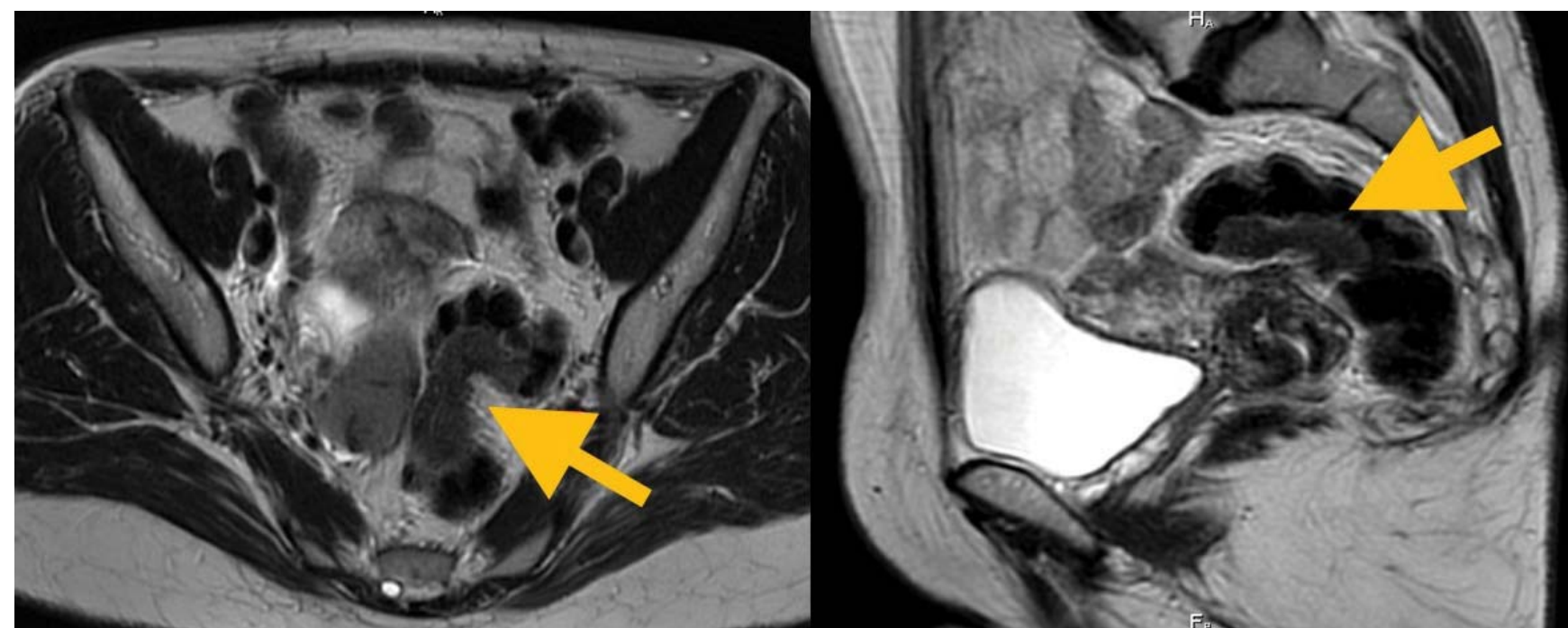

Figure 6. Pelvic MRI - Rectal endometriotic nodule with $50 \%$ mid rectum stenosis.

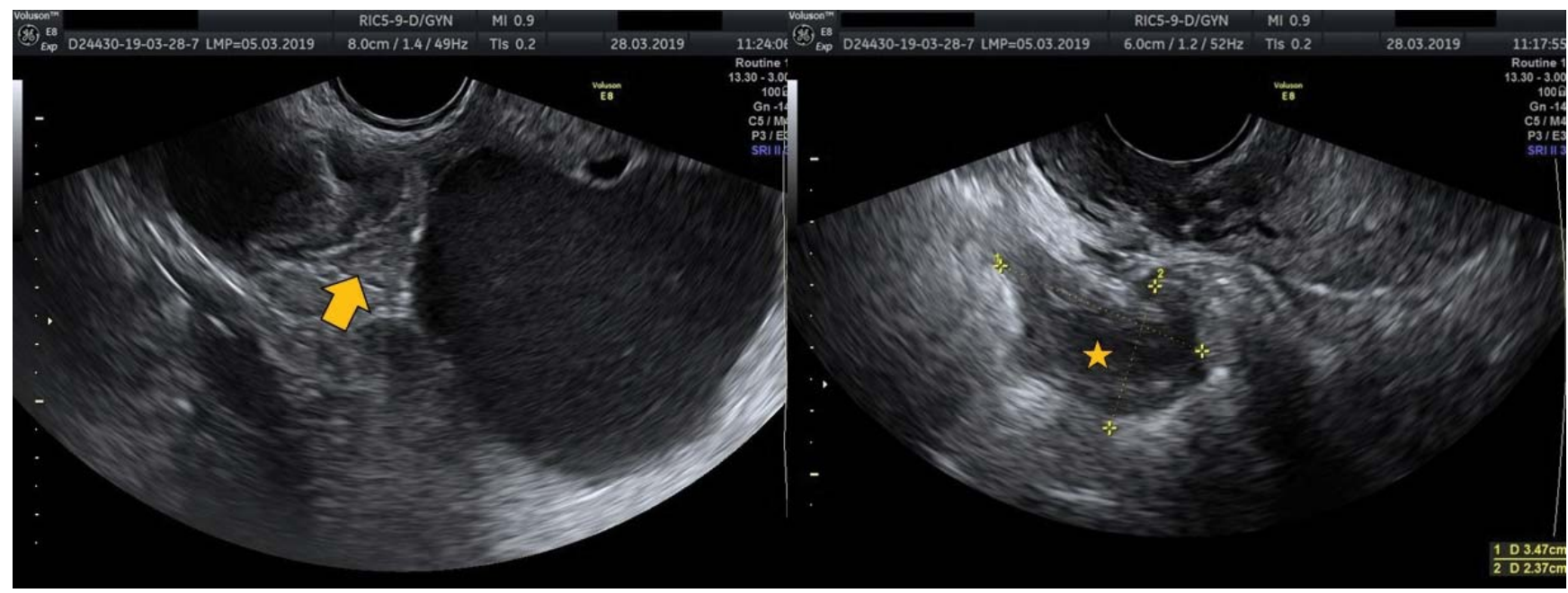

Figure 7. "Kissing ovaries" - arrow; Rectal endometriotic nodule - star.

3.8/2.3/1.5 $\mathrm{cm}$ rectal nodule at the level of the upper rectum/ rectosigmoid junction with $80 \%$ stenosis contrast medium reaches de lower border of the nodule but not more (Figure 8).

The position of the rectal nodule was estimated lower by transvaginal ultrasound because the uterus was hyper anteverted. If the uterus held its normal position, the nodule would have been located at the uterine fundus and at the level of the upper rectum/ rectosigmoid junction.
Given the pain score, severe quality of life impairment and high degree of stenosis, the patient was referred to a specialized center where she suffered rectosigmoid resection with termino-terminal anastomosis with no protective stoma. The postoperative course was uneventful and was certified by good EHP-30 score 13,89 - low level of quality of life impairment - dysmenorrhea VAS-3, dyspareunia VAS-2 and chronic pelvic pain VAS-2. 


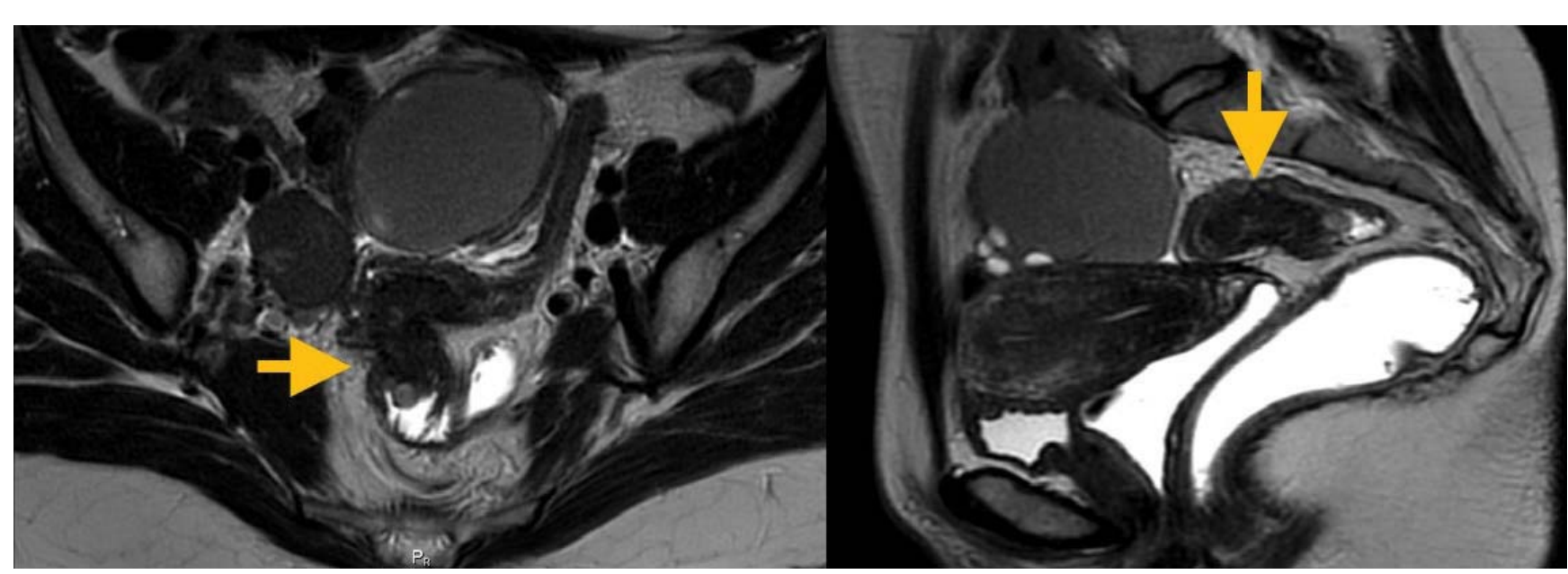

Figure 8. Pelvic MRI - Rectal endometriotic nodule with $80 \%$ upper rectum stenosis.

Case 3 - 39-year-old nulliparous woman with maximal impairment of quality of life shown by EHP-30 score-100 (maximal score), dysmenorrhea and dyspareunia VAS-10, chronic pelvic pain VAS-8, passing stool only with laxatives, no rectal bleeding.

The patient suffered 2 laparoscopic interventions for endometriosis in 2016 and 2018. In 2019, she was started $\mathrm{GnRH}$ antagonist medication for symptom control.

A large, well bordered, rectal nodule in contact with the posterior aspect of the uterus was demonstrated by ultrasound (Figure 9).
MRI scan revealed a large 5/3/1.6 cm nodule at the level of the upper rectum and rectosigmoid junction $(16 \mathrm{~cm}$ from the anal orifice). The nodule penetrates all the layers of the rectum determining $90 \%$ rectal stenosis and also infiltrates torus uterinus (Figure 10).

The patient was referred for rectal resection. Previous suboptimal treatment permitted the deep lesions to evolve, prevented conception and had a negative psychological impact on the patient that needed constant psychological counsel.

Figure 9. Endometriotic rectal nodule in contact with the posterior aspect of the uterus.

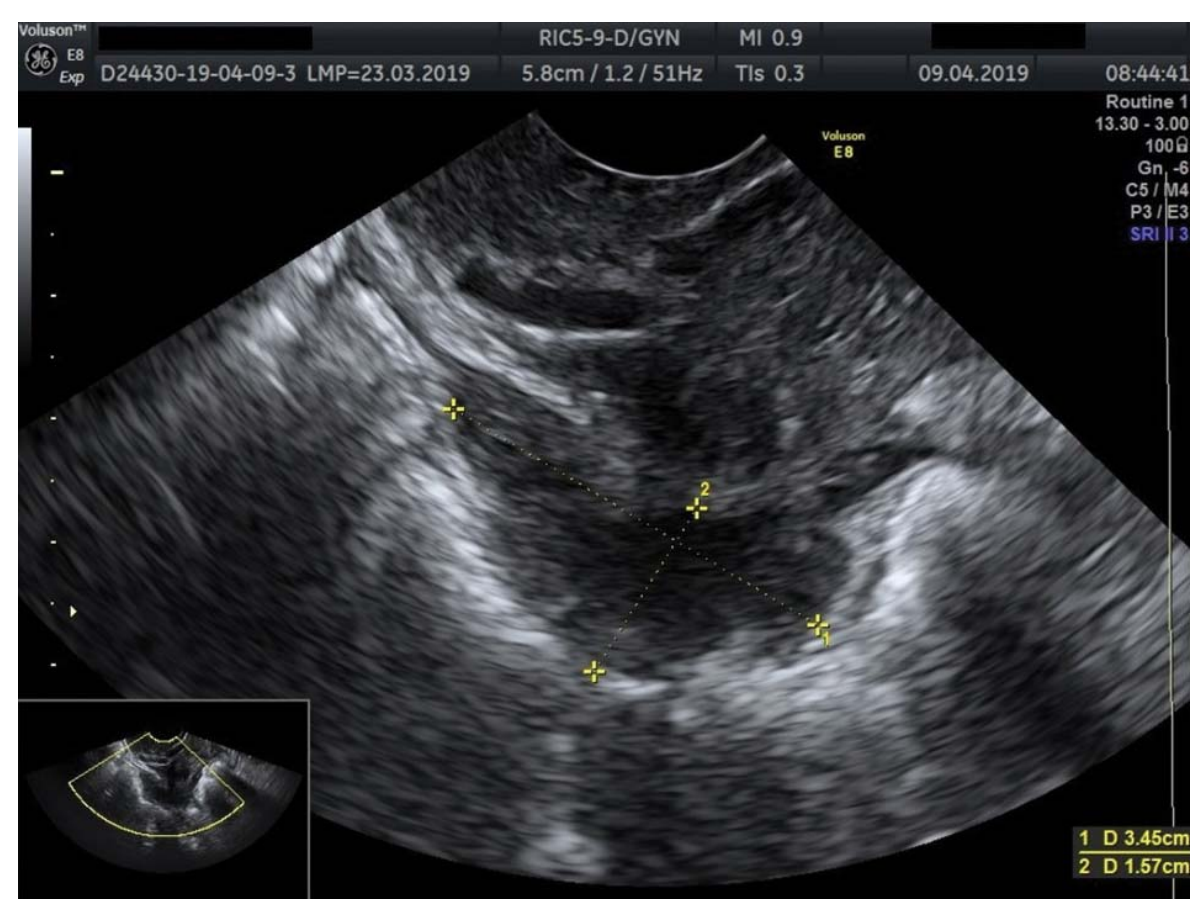




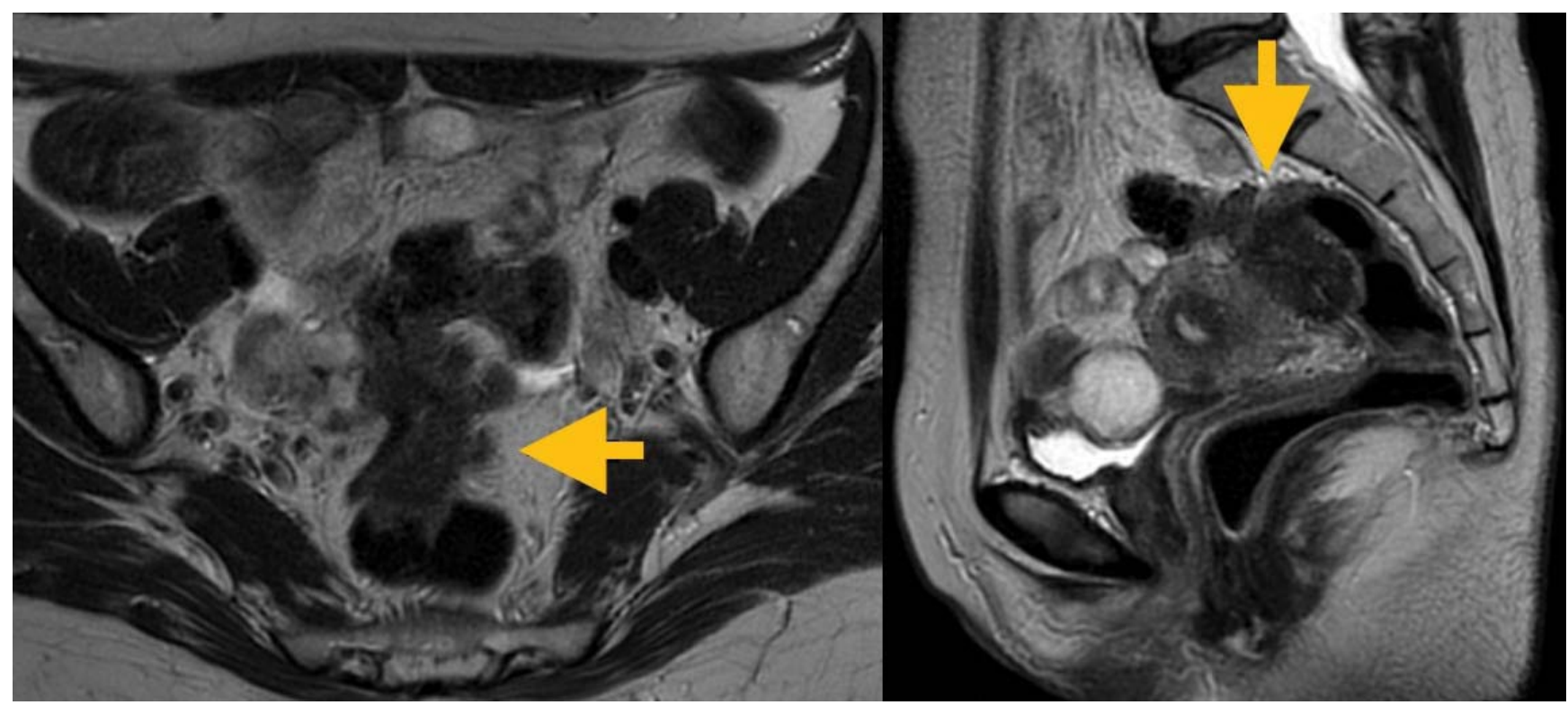

Figure 10. Pelvic MRI - Rectal endometriotic nodule with 90\% upper rectum stenosis.

Case 4 - 42-year-old referred for routine consultation. In depth anamnesis revealed right lumbar and vertebral pain referred to the posterior aspect of the right thigh and to the heel, pain enhanced by movement and during menstruation and chronic motor deficit. Previous neurology examination and initial MRI examination have stated that the patient suffered from lumbar disk disease and piriformis syndrome.

Barely in the reach of gynecology, the symptoms that worsened during menstruation drawn attention on endometriosis and the patient was referred for further imaging investigations in a specialized center.
Pelvic MRI demonstrated several T1 high intensity signal and T2 low intensity signal cystic lesions at the level of right sciatic nerve, anterior and inferior to the piriform muscle, consistent with the presence of an endometriotic nodule (Figure 11).

Sciatic nerve endometriosis implants are very rare extraperitoneal locations and should be taken into consideration in young women with catamenial sciatica associated with gluteal pain and motor deficit ${ }^{19}$. During MRI investigation, high matrix coronal and axial $\mathrm{T} 1$ and $\mathrm{T} 2$ weighted sequences are recommended to increase the diagnostic rate for this pathology.

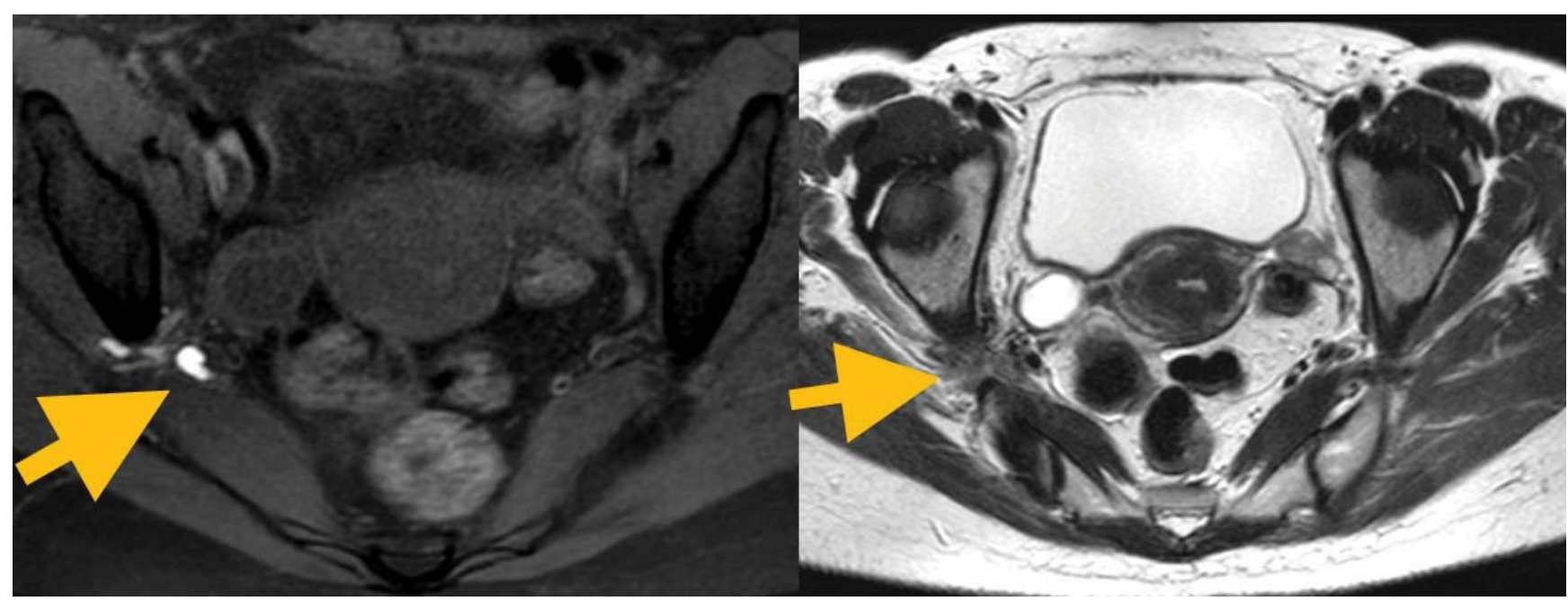

Figure 11. Pelvic MRI - cystic lesions at the level of right sciatic nerve - sciatic endometriotic nodule. 


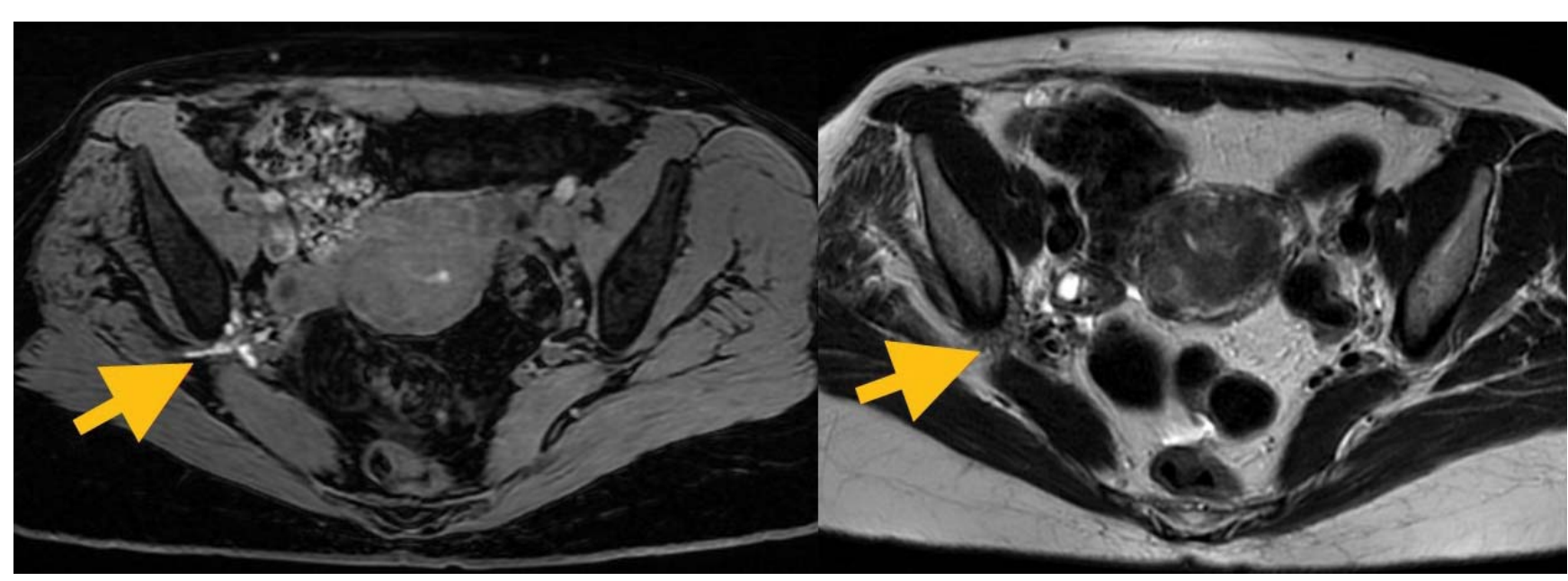

Figure 12. Pelvic MRI after treatment with Dienogest $-50 \%$ decrease of the sciatic endometriotic nodule.

Sciatic nerve endometriosis demands multidisciplinary management and requires highly experienced gynecological surgeons both in endometriosis and neuropelveology.

The patient refused surgical treatment intended to remove all endometriotic lesions and was started on Dienogest. Symptoms improved only after 3 months and at 1-year follow-up, chronic pelvic pain downgraded to VAS-7 to VAS-2 and the motor deficit was minimal. MRI at 1 -year has shown $50 \%$ decrease of the nodule (Figure 12).

Potential permanent damage to the sciatic nerve is prevented by early diagnosis and appropriate treatment.

\section{DISCUSSION}

The diagnosis of deep endometriosis is often challenging. Three main elements are required: firstly, we should think and raise clinical suspicion based on a complete anamnesis - questions like when, where, and how intense is the pain on a scale of $0-10$; secondly, ultrasound endometriosis specific markers should be identified, and then we must focus on each anatomical compartment in order to lower the rate of false diagnosis.

The delay in establishing the diagnosis is of worldwide concern: for example in Germany and Austria the average time from symptom onset to the positive diagnosis is 10.4 years $^{20}$, in Spain and U.K 8 and 7,9 years in USA ${ }^{21,22}$. The main issues for the delay, false negative diagnosis and underestimation of severity may arise from insufficient awareness of endometriosis by both patients and physicians and slow development of diagnosis and therapeutic skills.
The learning curve for transvaginal ultrasound is long, fact observed by Donnez in a study that involved experienced gynecologists that have performed at least 2500 general ultrasound examinations, without specialized experience in transvaginal examinations for endometriosis. After completion of training, the learning curve using the cumulative sum show that the subjects reached the level of proficiency for diagnostic rectal endometriosis after 37-42 patients scans ${ }^{23}$.

Regarding the MRI learning curve, L. Saba indicated a significant statistical difference in sensitivity regarding detection of recto-sigmoidian endometriotic nodules between first and third analysis: $39,1 \%$ versus with $82 \%{ }^{24}$.

\section{CONCLUSION}

The most important measures for early diagnosis of deep endometriosis are raised awareness for both patients and physicians and routine ultrasound examinations for symptomatic patients. Theoretical and practical training at profile conferences in order to enhance the ability of gynecologists to diagnose deep endometriosis should be encouraged.

Educational programs should be designed for both gynecologists and radiologists to improve collaboration. Feedback with operating room data or images might familiarize the radiologist with subtle surgical and pathology aspects.

Taking into consideration that deep endometriosis is a real public health problem increase efforts are mandatory to improve diagnostic and surgical skills. 
Compliance with ethics requirements: The authors declare no conflict of interest regarding this article. The authors declare that all the procedures and experiments of this study respect the ethical standards in the Hel- sinki Declaration of 1975, as revised in 2008(5), as well as the national law. Informed consent was obtained from all the patients included in the study.

\section{References}

1. Johnson NP, Hummelshoj L, Consortium WESM, Abrao M, Adamson G, Allaire $C$, et al. Consensus on current management of endometriosis. Human Reproduction. 2013;28(6):1552-68.

2. Piketty M, Chopin N, Dousset B, Millischer-Bellaische A-E, Roseau $\mathrm{G}$, Leconte $\mathrm{M}$, et al. Preoperative work-up for patients with deeply infiltrating endometriosis: transvaginal ultrasonography must definitely be the first-line imaging examination. Human Reproduction. 2008;24(3):602-7.

3. Guerriero S, Condous G, Van den Bosch T, Valentin L, Leone F, Van Schoubroeck D, et al. Systematic approach to sonographic evaluation of the pelvis in women with suspected endometriosis, including terms, definitions and measurements: a consensus opinion from the International Deep Endometriosis Analysis (IDEA) group. Ultrasound in Obstetrics \& Gynecology. 2016;48(3):318-32.

4. Bazot M, Bharwani N, Huchon C, Kinkel K, Cunha TM, Guerra A, et al. European society of urogenital radiology (ESUR) guidelines: MR imaging of pelvic endometriosis. European radiology. 2017;27(7):2765-75

5. Guerriero S, Ajossa S, Orozco R, Perniciano M, Jurado M, Melis $G$, et al. Accuracy of transvaginal ultrasound for diagnosis of deep endometriosis in the rectosigmoid: systematic review and meta analysis. Ultrasound in Obstetrics \& Gynecology. 2016;47(3):281-9.

6. Medeiros LR, Rosa MI, Silva BR, Reis ME, Simon CS, Dondossola ER, et al. Accuracy of magnetic resonance in deeply infiltrating endometriosis: a systematic review and meta-analysis. Archives of gynecology and obstetrics. 2015;291(3):611-21.

7. Moore J, Copley S, Morris J, Lindsell D, Golding S, Kennedy S. A systematic review of the accuracy of ultrasound in the diagnosis of endometriosis. Ultrasound in Obstetrics and Gynecology: The Official Journal of the International Society of Ultrasound in Obstetrics and Gynecology. 2002;20(6):630-4.

8. Massein A, Petit E, Darchen M, Loriau J, Oberlin O, Marty O, et al. Imaging of intestinal involvement in endometriosis. Diagnostic and interventional imaging. 2013;94(3):281-91.

9. Brosens I, Puttemans P, Campo R, Gordts S, Kinkel K. Diagnosis of endometriosis: pelvic endoscopy and imaging techniques. Best practice \& research Clinical obstetrics \& gynaecology. 2004;18(2):285-303.

10. Ghezzi F, Raio L, Cromi A, Duwe DG, Beretta P, Buttarelli M, et al. "Kissing ovaries": a sonographic sign of moderate to severe endometriosis. Fertility and sterility. 2005;83(1):143-7.

11. Savelli L, Manuzzi L, Pollastri P, Mabrouk M, Seracchioli R, Venturoli S. Diagnostic accuracy and potential limitations of transvaginal sonography for bladder endometriosis. Ultrasound in Obstetrics and Gynecology: The Official Journal of the International Society of Ultrasound in Obstetrics and Gynecology. 2009;34(5):595-600.

12. Exacoustos $C$, Manganaro L, Zupi E. Imaging for the evaluation of endometriosis and adenomyosis. Best practice \& research Clinical obstetrics \& gynaecology. 2014;28(5):655-81.
13. Holland TK, Cutner A, Saridogan E, Mavrelos D, Pateman K, Jurkovic D. Ultrasound mapping of pelvic endometriosis: does the location and number of lesions affect the diagnostic accuracy? A multicentre diagnostic accuracy study. BMC women's health. 2013;13(1):43.

14. Hudelist G, Ballard K, English J, Wright J, Banerjee S, Mastoroudes $\mathrm{H}$, et al. Transvaginal sonography vs. clinical examination in the preoperative diagnosis of deep infiltrating endometriosis. Ultrasound in Obstetrics \& Gynecology. 2011;37(4):480-7.

15. Hudelist G, English J, Thomas A, Tinelli A, Singer C, Keckstein $J$. Diagnostic accuracy of transvaginal ultrasound for non invasive diagnosis of bowel endometriosis: systematic review and meta analysis. Ultrasound in Obstetrics \& Gynecology. 2011;37(3):257-63.

16. Gui B, Valentini AL, Ninivaggi V, Micco M, Zecchi V, Grimaldi PP, et al. Shining light in a dark landscape: MRI evaluation of unusual localization of endometriosis. Diagnostic and Interventional Radiology. 2017;23(4):272.

17. Dousset $B$, Leconte $M$, Borghese B, Millischer A-E, Roseau $G$, Arkwright $\mathrm{S}$, et al. Complete surgery for low rectal endometriosis: long-term results of a 100-case prospective study. Annals of surgery. 2010;251(5):887-95.

18. Abrão MS, Podgaec S, Dias Jr JA, Averbach M, Silva LFF, de Carvalho FM. Endometriosis lesions that compromise the rectum deeper than the inner muscularis layer have more than $40 \%$ of the circumference of the rectum affected by the disease. Journal of minimally invasive gynecology. 2008;15(3):280-5.

19. Niro J, Fournier M, Oberlin C, Le Tohic A, Panel P. Endometriotic lesions of the lower troncular nerves. Gynécologie Obstétrique \& Fertilité. 2014;42(10):702-5.

20. Hudelist G, Fritzer N, Thomas A, Niehues C, Oppelt P, Haas D, et al. Diagnostic delay for endometriosis in Austria and Germany: causes and possible consequences. Human reproduction. 2012;27(12):3412-6.

21. Ballard K, Lowton K, Wright J. What's the delay? A qualitative study of women's experiences of reaching a diagnosis of endometriosis. Fertility and sterility. 2006;86(5):1296-301.

22. Nnoaham KE, Hummelshoj L, Webster $P$, d'Hooghe $T$, de Cicco Nardone F, de Cicco Nardone $C$, et al. Impact of endometriosis on quality of life and work productivity: a multicenter study across ten countries. Fertility and sterility. 2011;96(2):366-73. e8.

23. Tammaa A, Fritzer N, Strunk G, Krell A, Salzer H, Hudelist G. Learning curve for the detection of pouch of Douglas obliteration and deep infiltrating endometriosis of the rectum. Human reproduction. 2014;29(6):1199-204.

24. Saba L, Guerriero S, Sulis R, Pilloni M, Ajossa S, Melis G, et al. Learning curve in the detection of ovarian and deep endometriosis by using Magnetic Resonance: comparison with surgical results. European journal of radiology. 2011;79(2):237-44. 
